\title{
Involving patients and the public in the NHS
}

\author{
Christopher Clough
}

ABSTRACT - Involving patients and the public in the NHS is a new strategic initiative by the Deparment of Health. Over time it will make a significant change to how services are designed and delivered. Doctors need to be aware of this new legislation and the change in the patient/clinician dynamic it embraces. In the clinical setting a change of culture is required so that doctors move to working in partnerships with their patients. Within trusts, hospital or otherwise, structures must be in place to ensure appropriate patient/public involvement. Health service workers and the public will need to understand the skills required from both sides for a constructive partnership to emerge. It is hoped that the prioritising of health service resources in the future will be the result of a more democratic process involving patients, public and health service workers.

KEY WORDS: Local Strategic Partnerships (LSP), modernisation, Oversee and Scrutiny Committee (OSC), patient advocacy and liaison services (PALS), patient/public involvement (PPI), strengthening accountability

A patient is the most important person in our hospital. He is not an interruption to our work, he is the purpose of it. He is not an outsider in our hospital. He is part of it.

(Bombay Hospital motto attributed to Mahatma Gandhi)

Section II of the Health and Social Care Act 2001 Strengthening accountability ${ }^{1}$ - enshrined in law a legal duty for NHS organisations to involve and consult patients and the public in the planning of service provision, the development of proposals for and decisions about how services operate. These principles (Box 1) were set out in the Kennedy Report on the Bristol Royal Infirmary $(2001)^{2}$ and are intended to lead to genuine patient and public involvement (PPI), and greater openness in decision making. Four out of the 10 principal NHS Plans directly support PPI, stating that the NHS will:

- shape its services around the needs of individual patients, their families and their carers

- respond to different needs of different populations

- work together with others to ensure a seamless service for patients
- respect the confidentially of individual patients and provide access to information about services, treatment and performance.

Although this Act only applies to the UK, patient empowerment is a world-wide phenomenon reflecting a shift in the balance of power in the relationship between doctors and the patients and public. The NHS has taken a lead which is being watched closely by other health services. Doctors may feel threatened by this cultural change, but should recognise that involving patients in the management of their care could bring major benefits for all. It is hoped that this move will make the NHS more patient-centred and enable patients to become true partners in their care.

\section{Why do this? Reasons for change}

At present there is little evidence to suggest that increasing patient/public involvement (PPI) will necessarily improve the service delivered by the NHS. Intuitively it seems likely that PPI will highlight those consumer aspects of the service that in the past professionals may have neglected, eg access to the service, the environment in which it is delivered and the behaviour/attitude of the staff. Clinicians, when allocating resource, have given more weight to other aspects of the service, ie diagnostics and therapeutics. This is in line with those studies which show considerable variance between what patients say they want

Box 1. Practice guidance 14 (from Strengthening accountability). ${ }^{1}$

- Patients and the public are entitled to be involved wherever decisions are taken about care in the NHS.

- The involvement of patients and the public must be embedded in the structures of the NHS and permeate all aspects of healthcare.

- The public and patients should have access to relevant information.

- Healthcare professionals must be partners in the process of involving the public and patients.

- There must be honesty about the scope of the public's and patients' involvement, since some decisions cannot be made by the public.

- There must be transparency and openness in the procedures for involving the public and patients.

- The mechanisms for involvement should be evaluated for their effectiveness.

- The public and patients should have access to training and funding to allow them to participate fully.

- The public should be represented by a wide range of individuals and groups, and not by particular 'patient groups'. 
from a doctor and what doctors think patients want. One questionnaire study showed that patients wanted to be respected, listened to and valued as people, whereas the doctor put cure as patients' main priority. ${ }^{3}$ Similarly, quality-of-life studies demonstrate a difference between the patient's point of view and that of a doctor. For example, patients with Parkinson's disease were more worried about depression and mental health, whereas the doctor's main concern was their mobility and pharmacotherapy. 4

The patient's perspective will shift the direction of how health services are provided. This is in many ways similar to consumer testing which has informed best business practice. The political perspective is that public involvement should change public services, so it is an attempt to change state-run services by giving the 'citizen' rights. This initiative is combined in England with the policy of 'patient choice' whereby patients choose where they want to have their treatment. Private practice in medicine can deliver choice effectively. However, the disadvantage of private medicine is that it leaves the buyer of services open to unscrupulous providers, especially where professional services are poorly understood by the public and there is a lack of information about costs versus benefits, quality and risk. Crucially, private medicine also disenfranchises the poor. Alternatively, the trumpeted Third Way offers a halfway house whereby primary care trusts act as advocates to patients, effectively spending health money on their behalf, providing them with appropriate advice on when and where to seek specialist help and, lastly, giving patients a limited choice of treatment centres. The PPI initiative is the other side of this, enabling the public to take part in the debate on how to design services and allocate resource. It has the political strength to devolve some decision-making to the public, so when the time comes to prioritise health spending (ie ration) the public will hopefully be involved in these difficult decisions.

\section{What does it mean?}

Most professionals do not seek to exclude patients, rather they genuinely, often mistakenly, believe they are involving them.

(Kennedy 2003) $)^{5}$

When dealing with patients face-to-face, doctors should move away from a traditional paternalistic approach - telling, informing - to one which brings the patient into a partnership (see Table 1) - advising, guiding, agreeing management plans and offering choices. Doctors often talk of patients failing to comply with treatment, which assumes that 'doctor knows best' and that not obeying instructions is a failure on the patient's part. By contrast, doctors should seek 'concordance' - agreeing on a course of action after full discussion of the pros and cons of treatment, and respecting the patient's wishes; then 'adherence' to agreed treatment will be more likely. Many doctors already practise in this way, notably in palliative medicine and psychiatry. It takes resources to do this, not only in staff training but also in time spent with the patient. Many of us will need to change our way of working. Already we attempt to achieve far too much within short outpatient consultations. To involve patients, doctors will need to work within their teams and decide what tasks can reasonably be achieved within the allotted time. Nurses and others can take on parts of the consultation, and spend more time explaining and advising. Specialist nurses have proved very successful in their role, mainly because they spend time with patients. Patients may need days or weeks to make some decisions and the option of checking back to somebody with expertise for advice. Clinical teams will need to arrange appropriate communication pathways. Some doctors already have phone clinics, give email addresses or use text messaging to enhance the exchanges of information required to make a good decision.

\section{Where do we go from here?}

From now on, involving the patients and public should be the starting point of change in health services. They should be involved in determining local priorities, strategic policymaking, service development and treatment processes. The Modernisation Agency identifies three areas of involvement: ${ }^{6}$

- information

- consultation

- partnership.

Doctors will probably be involved with service development and treatment, and will want to work in partnerships. How best to do this? Table 1 outlines the differences between what happened in the past - the expert advisor model - and how we should now work - the partnership model.

Before starting, we need to understand the genuine anxieties that both patients and staff might have about working in this way. Patients will worry that their opinions will not be valued, that they are not as fully informed as the professionals, and might look foolish, or not understand what is going on. Also, they may be anxious about causing offence to medical staff and others, which might affect their treatment. Staff, on the other hand, may be concerned that they will be criticised and their authority undermined, leading to loss of confidence in them as practitioners if they are seen to be vulnerable. Managers will worry that patients will have unrealistic demands and not understand the resource restrictions circumscribing their work. Leaders of change therefore need to make it clear to their team that better decisions are made when patients' views and perspectives are heard: alternative proposals may be developed;

Table 1. Comparison of previous expert advisor model with new partnership model.

\begin{tabular}{ll}
\hline Expert advisor & Partnership \\
\hline Define patient needs & Elicit patient needs \\
Give advice & Discuss options \\
Solve problems & Explore solutions \\
Decide what information & Ask what information \\
patients need & patients want \\
Encourage dependency & Empower and enable
\end{tabular}


understanding the patient experience will benefit others and lead to more responsive services. Conversely, patients will need to learn that constructive team playing is more likely to bring out the best in staff, and be more productive than the confrontational approach staff have experienced in the past from some groups such as the community health councils.

All trusts are now required to have a PPI strategy and now have patient advocacy and liaison services (PALS). These teams may be the resource used to champion PPI although they have a specific role managing complaints and advocacy; there is therefore an argument that PPI is best kept separate though linked to PALS. The trust will need to demonstrate PPI in its local development plans agreed with primary care trusts (PCTs) and signed off by the health authority. Local councils are required to set up Oversee and Scrutiny Committees (OSCs) which involve the public and must be aware of all new developments within the trust. Local Strategic Partnerships (LSPs) bring together the public sector with the voluntary, community and private sectors as a forum for coordinating plans, developing community and neighbourhood renewal strategies, developing local public service agreements and rationalising strategic partnership working. They will also involve PCTs as health representatives. Nationally, there is a Commission for Patient and Public Involvement with Health $(\mathrm{CPPI} / \mathrm{H})$ with three core functions:

- advising and assisting patient forums

- representing the voice of patient forums and other patient groups to the Secretary of State

- promoting at a national level the involvement of the public in health matters.

The Modernisation Agency has produced a booklet outlining an approach to PPI. ${ }^{6}$ The level of involvement will vary considerably with the type of project - at its lowest level there may only be a need for information giving (eg through leaflets, the press). At the next level, patients might be involved through selfcompleted questionnaires, semi-structured one-to-one interviews or in citizens' panels. Forums for debate could include focus groups, public meetings or seminars held for people with a particular interest. Participation at a higher level could include using expert patients, shadowing patients and story telling. (Story telling is hearing directly from patients about their experience of health services. Often structured interviews within the patient's home is the best way to carry this out.) Full partnership working should be the aim, and may require large group processes (eg whole system approaches).

\section{Who should be involved?}

A good patient should learn everything he can about his illness or disability.

(Christopher Reeve, June 2003) ${ }^{5}$

Involving patients and the public - the users of the service - will bring difficulties. How best to do this? User involvement should add value and be constructive, and users should be representative of their constituency. Users are not to be seen as a free gift,

\section{Key Points}

Patient public involvement will lead to changes in the way healthcare services are designed and delivered

The public must be involved in all future design of healthcare services

Doctors should work in partnership with their patients and agree investigation and treatment plans

Initial consultation should be allocated appropriate time to achieve these goals

Doctors need to work in partnership with others for effective communication with patients

brought in because we've been told to involve them. There has been little research into how to find users appropriate to the purpose, what criteria to use to select them, and how best to encourage applicants and reward them for their efforts. The public can be easily alienated by the format of meetings and the conduct and language used by professionals, so participants should be aware of this. Meetings should be accessible to those in work, those bringing up families and retired people. Meetings and other user input (eg questionnaires) should be conducted to give maximum value.

It is important to think carefully about who to involve, as the temptation will be to involve known patients, creating an opportunity for the privileged patient to have a prominent role in healthcare planning. It is important to seek out groups which are harder to reach and to access alternative views. Although expert patients or good patients have their place, troublesome or difficult patients may give greater value. The Department of Health has offered the following guidelines on who to involve:

- those who use the service as well as those waiting or who potentially will use the service at some point

- people who do not access the service despite a need

- others as appropriate:

- local people

- pressure groups

- gender-, disability- and ethnicity-specific groups

- community groups and activitists

- friends and families of patients

- inaccessible groups

- people who have identified issues - complaints, PALS

- staff.

If advertising for appropriate people, it is particularly important to spell out the support they can expect in post. Their expenses must be covered, or they can be paid directly for their contribution - after all they will be in a room of professions who will definitely be expecting to be paid for their time. Support also consists of giving timely information and advice and someone in the trust to call upon for help. Feedback to those involved is important in establishing trust and evidence that their involvement has made a difference. 


\section{Conclusion}

A lot of it is just listening to them.

Involving the patients and public in decision making in healthcare is a significant change, and will be important as we move away from covert (implicit) rationing of resources by health professionals towards the more reasonable approach of overt (explicit) rationing of resources. Civilised societies raise tax for health purposes in order to improve the quality and duration of life of their citizens. The public need to be involved in setting health priorities and determining the breadth and quality of health services where there is a fixed resource, so that these processes are seen to be just. PPI in all aspects of healthcare planning is likely to be the best way of achieving reasonable solutions, owned by the public, to the difficult problems of rationing healthcare in the future. Doctors should embrace these changes and look forward to an equal partnership with their patients - not only in the consulting room, but also in the planning of health services.

\section{References}

1 Strengthening accountability - Involving patients and the public. Section 11 of the Health and Social Care Act 2001.

2 Learning from Bristol: the report of the public inquiry into children's heart surgery at the Bristol Royal infirmary 1984-1995 (CM 52071). London: The Stationery Office, 2001.

3 Parkinson's disease: the personal view. Training video. London: PDS UK and Yey TV, 1990.

4 Factors impacting on quality of life in Parkinson's disease: Results from an international survey. The Global Parkinson's Disease Surgery (GPDS) Steering Committee. Mov Disord 2002;17:60-67.

5 BMJ 2003;7402 (14 June). Special edition devoted to the patient-doctor relationship.

6 NHS Modernisation Agency. Involving patients and carers. Ipswich: Ancient House Printing Group, 2002. 